\title{
PENGARUH SENAM OTAK (BRAIN GYM) TERHADAP TINGKAT STRES MAHASISWA (STUDI DILAKUKAN PADA MAHASISWA SEMESTER 8 PRODI KEPERAWATAN STIKES WIRA MEDIKA BALI)
}

\section{THE EFFECTS OF BRAIN GYM TOWARD STUDENT STRESS LEVELS. STUDY CONDUCTED ON SEMESTER 8 STUDENTS OF NURSING STUDY PROGRAM AT STIKES WIRA MEDIKA BALI}

\author{
M Andre Marantika ${ }^{1}$, A.A Sri Agung Adilatri ${ }^{2}$,Ika Setya Purwanti ${ }^{3}$ \\ ${ }^{1,2,3}$ Program Studi Keperawatan STIKes Wira Medika Bali ${ }^{1,2,3}$
}

\begin{abstract}
ABSTRAK
Selama proses penyusunan skripsi mahasiswa ditantang dan dilatih untuk melakukan serangkaian kegiatan yang bersifat ilmiah yang menguji suatu teori dan memecahkan suatu permasalahan dengan pola pikir yang kritis (critical thinking). Stres mahasiswa dalam menyusun skripsi, disebabkan karena susahnya mencari referensi dan tekanan tugas yang deadline. Salah satu terapi untuk menurunkan stres adalah terapi senam otak (Brain Gym). Tujuan penelitian ini untuk mengetahui pengaruh terapi senam otak (Brain Gym) terhadap tingkat stres mahasiswa. Penelitian ini menggunakan metode pra-eksperimen dengan rancangan one group pre test-post test. Sampel dalam penelitian ini didapatkan 66 orang dengan tehnik simple random sampling. Penelitian dilaksanakan di Stikes Wira Medika Bali. Tingkat stres diukur dengan kuesioner DASS 42. Hasil penelitian didapatkan tingkat stres mahasiswa sebelum diberikan senam otak (Brain Gym) sebanyak 43 orang dengan kategori tingkat stres sedang, dan tingkat stres mahasiswa setelah diberikan terapi senam otak (Brain Gym) 50 orang dengan kategori tingkat stres ringan. Hasil uji statistic Wilcoxon Signed Rank Test dengan tingkat kemaknaan 0,05 menunjukan nilai $\mathrm{p}=0,000<0,05$. Kesimpulan penelitian, ada pengaruh senam otak (Brain Gym) terhadap tingkat stres mahasiswa. Berdasarkan hasil penelitian tersebut disarankan bagi yang mengalami stres dalam mengerjakan tugas akhir dapat menggunakan terapi senam otak (Brain Gym) tersebut untuk mengurangi tingkat stres.
\end{abstract}

Kata kunci : Stres, Senam Otak (Brain Gym), Tingkat Stres Mahasiswa

ABSTRACT

During the process of preparing the thesis students are challenged and trained to carry out a series of scientific activities that test a theory and solve a problems with a critical mindset (critical thinking). Students' stress in compiling a thesis is due to difficulty in finding 
BMJ. Vol 6 No 2, 2019: 155-162

DOI: https://doi.org/10.36376/bmj.v6i2

references and deadline task pressure. One of the therapies to decrease stress level is brain gym therapy. The aimed of this study was to determine the effect of brain gym on college student stress level. This study used pra-experiment method with one group pre-test-posttest design. The number of samples in this study were 66 students with simple random sampling techniques. The research was conducted at Stikes Wira Medika Bali. Stress levels were measured by the DASS 42 questionnaire. The results showed that the stress levels of students before being given brain gym were 43 people with moderate stress level category and student stress levels after being given brain gym therapy with 50 people with light stress levels. The results of the Wilcoxon Signed Rank Test statistical test with a significance level of 0.05 indicate the value of $p=0.000<0.05$. This study concludes that there is an effect of brain gymnastic on student stress level. Based on the results of this study, it is recommended for the college student who is experiencing stress during writing their thesis could use brain gym for reducing stress level.

Keywords : Stress, Brain gym, College student stress level

\author{
Alamat Korespondensi $\quad$ : Jl. Kecak No.9A, Tonja, Kec. Denpasar Utara, Kota Denpasar. \\ Email : Madeandre030297@gmail.com
}

\title{
PENDAHULUAN
}

Mahasiswa adalah sekumpulan orang yang sedang menuntun ilmu di perguruan tinggi. Mahasiswa dipersiapkan menjadi sumber daya manusia yang mampu menghadapi persaingan global, sehingga sampai saat ini mahasiswa masih menjadi tumpuan dan harapan bangsa. Sebagai syarat kelulusan pada mahasiswa tingkat akhir salah satunya mengerjakan tugas akhir yang sering disebut skripsi (Susane,2017).

Selama proses penyusunan skripsi mahasiswa ditantang dan dilatih untuk melakukan serangkaian kegiatan yang bersifat ilmiah yang menguji suatu teori dan memecahkan suatu permasalahan dengan pola pikir yang kritis ( critical thinking), dalam proses tersebut tidak semua mahasiswa mempunyai kesiapan dalam mengerjakan skripsi, banyak mahasiswa yang sedang menyusun skripsi merasa beban yang berat, akibatnya kesulitan-kesulitan yang dirasakan tersebut berkembang menjadi perasaan negative yang akhirnya dapat menimbulkan ketegangan, kekhawatiran dan stres ( Susane, 2017 ).

Mahasiswa mengalami stres dari berbagai sumber, baik masalah akademik yang kaitannya dengan kegagalan mahasiswa dalam menyelesaikan tuntutan akademik, penundaan penyelesaian tugas, prestasi akademik yang rendah, dan masalah kesehatan. Sumber stres akademik meliputi yang seperti, kebisingan, tugas yang terlalu banyak, harapan yang tidak sesuai keinginan , ketidakjelasan, kurang adanya control keadaan bahaya dan kritis, tidak dihargai, diacuhkan, kehilangan kesempatan, aturan yang membingungkan, tuntutan yang saling bertentangan, dan deadline tugas perkuliahan (Rahayu, 2017).

Menurut Ni'matuzahroj (2016). Stres akademik merupakan situasi tertekan yang dialami seseorang dimana terdapat tuntutan akademik yang ditandai dengan berbagai macam reaksi yang meliputi reaksi fisik, emosi, kognitif dan tingkah laku. Reaksi ini pada umumnya di tandai dengan reaksi fisik berupa pusing, sakit perut, 
DOI: https://doi.org/10.36376/bmj.v6i2

reaksi emosi berupa perasaan sedih, marah dan menangis, reaksi kognitif seperti susah berkonsentrasi saat belajar, insomnia, sedangkan reaksi tingkah laku seperti berteriak, melempar benda dan masih banyak lainnya. Remaja sering mengalami stres akademik diakibatkan dari tuntutan baik dari dalam diri maupun luar diri individu sang anak.

Menurut WHO (2012), satu dari lima remaja pada usia dibawah 15 tahun memiliki masalah kesehatan jiwa akibat stres, dan 3-4\% dari kelompok usia tersebut memiliki masalah kesehatan jiwa serius yang memerlukan penanganan memadai dan profesional sedangkan menurut Depkes RI (2012), tercatat jumlah remaja yang mengalami gangguan kejiwaan atau stres sekitar $11,6 \%$ dari populasi Indonesia sekitar 24.708.000 orang. Di Bali juga mengalami kemajuan zaman khususnya di daerah Kota Denpasar. Pada tahun 2012 stres pada remaja yang berumur di bawah 18 tahun lebih tinggi yaitu sekitar 14,6\% dari populasi di Bali sekitar 1.065.000 orang. ( Badan pusat Statistik Bali,2012).

Hasil survey yang dilakukan oleh American Collage Health Association (ACHA) pada tahun 2013 di Amerika, menjelaskan salah satu masalah besar yang dihadapi mahasiswa dalam dunia perkuliahan adalah stres. Sebanyak $27,9 \%$ dari total 32.964 mahasiswa mengakui bahwa stres menjadi penghalang bagi performa akademik mereka. Berdasarkan penelitian Abdulghani (2014) di Saudi Arabia, diketahui bahwa pravelensi stres pada mahasiswa tahun pertama sebanyak 78,8\%. Hasil ini merupakan angka tertinggi dibandingkan dengan angkat tahun-tahun di atasnya.

\section{METODE PENELITIAN}

Desain penelitian dalam penelitian ini adalah pre -exsperimental yaitu one group pretest-posttest,. Penelitian ini dilakukan di STIKes Wira Medika Bali, populasi angkatan 9 dengan jumlah 193 dan yang digunakan sampel sebanyak 66 responden. Sampling dalam penelitian ini menggunakan Probability Sampling dengan tehnik Simple Random Sampling. uji normalitas data menggunakan Shapiro Wilk dan data berdistribusi normal maka digunakan uji Willcoxon. data pada variabel bebas memiliki skala ordinal dan data variabel terikat memiliki skala ordinal.

\section{HASIL DAN PEMBAHASAN}

\section{HASIL}

Karakteristik responden.

Table 1. Distribusi responden jenis kelamin

\begin{tabular}{cccccc}
\hline & & Frequency & Percent & Valid Percent & $\begin{array}{c}\text { Cumulative } \\
\text { Percent }\end{array}$ \\
\hline \multirow{2}{*}{ Valid } & Laki-Laki & 16 & 24.2 & 24.2 & 24.2 \\
\cline { 2 - 6 } & Perempuan & 50 & 75.8 & 75.8 & 100.0 \\
\cline { 2 - 6 } & Total & 66 & 100.0 & 100.0 & \\
\hline
\end{tabular}

Berdasarkan Tabel 1 menunjukan bahwa sebagian besar responden berjenis kelamin perempuan sebanyak 50 orang $(75,8 \%)$. 
BMJ. Vol 6 No 2, 2019: 155-162

ISSN : 2615-7047

DOI: https://doi.org/10.36376/bmj.v6i2

Tabel 2. Distribusi responden berdasarkan umur

\begin{tabular}{cccccc}
\hline & & Frequency & Percent & Valid Percent & $\begin{array}{c}\text { Cumulative } \\
\text { Percent }\end{array}$ \\
\hline \multirow{2}{*}{ Valid } & 21 & 32 & 48.5 & 48.5 & 48.5 \\
\cline { 2 - 6 } & 22 & 34 & 51.5 & 51.5 & 100.0 \\
\cline { 2 - 6 } & Total & 66 & 100.0 & 100.0 & \\
\hline
\end{tabular}

Berdasarkan tabel 2 menunjukan bahwa sebagian besar responden berusia 22 tahun yaitu sebanyak 34 orang $(51.5 \%)$.

Tabel 3. Distribusi Frekuensi Tingkat Stres Sebelum diberikan Senam Otak ( Brain Gym )

\begin{tabular}{cccccc}
\hline & & Frequency & Percent & Valid Percent & Cumulative Percent \\
\hline \multirow{2}{*}{ Valid } & Normal & 0 & 0 & 0 & 0,0 \\
\cline { 2 - 6 } & Ringan & 20 & 30.3 & 30.3 & 30.3 \\
\cline { 2 - 6 } & Sedang & 43 & 65.2 & 65.2 & 95.5 \\
\cline { 2 - 6 } & Berat & 3 & 4.5 & 4.5 & 100.0 \\
\cline { 2 - 6 } & Total & 66 & 100.0 & 100.0 & \\
\hline
\end{tabular}

Berdasarkan tabel 3 dapat dilihat bahwa tingkat stres responden sebelum dilakukan terapi senam otak (Brain Gym) sebagian besar responden.

Tabel 4. Distribusi Frekuensi Tingkat Stres Setelah diberikan Senam Otak ( Brain Gym )

\begin{tabular}{cccccc}
\hline \multirow{7}{*}{ Valid } & & Frequency & Percent & Valid Percent & $\begin{array}{c}\text { Cumulative } \\
\text { Percent }\end{array}$ \\
\cline { 2 - 6 } & normal & 16 & 24.2 & 24.2 & 24.2 \\
\cline { 2 - 6 } & Ringan & 50 & 75.8 & 75.8 & 100.0 \\
\cline { 2 - 6 } & Sedang & 0 & 0,0 & 0 & 0,0 \\
\cline { 2 - 6 } & Berat & 0 & 0,0 & 0 & 0,0 \\
\cline { 2 - 6 } & Total & 66 & 100.0 & 100.0 & \\
\hline
\end{tabular}

Berdasarkan tabel 4 dapat dilihat bahwa tingkat stres setelah dilakukan terapi Senam Otak (Brain Gym) sebagian besar responden berada pada tingkat stres ringan dengan 50 responden $(75,8 \%)$ dan normal 16 responden $(24,2)$.

Tabel 5.Distribusi Frekuensi analisa pengaruh senam otak terhadap tingkat stres mahasiswa.

\begin{tabular}{cccccc}
\hline \multirow{2}{*}{$\begin{array}{c}\text { Kategori } \\
\text { tingkat } \\
\text { stres }\end{array}$} & \multicolumn{2}{c}{ Hasil pre test } & \multicolumn{2}{c}{ Hasil post test } & \multirow{2}{*}{ P Value } \\
\cline { 2 - 5 } & frekuensi & $\begin{array}{c}\text { Persentase } \\
(\%)\end{array}$ & frekuensi & $\begin{array}{c}\text { Persentase } \\
(\%)\end{array}$ & \\
\hline Normal & 0,0 & 0,0 & 16 & 24.2 & \multirow{2}{*}{0,000} \\
\hline Ringan & 20 & 30.3 & 50 & 75.8 & \\
\hline
\end{tabular}


BMJ. Vol 6 No 2, 2019: 155-162

ISSN : $2615-7047$

DOI: https://doi.org/10.36376/bmj.v6i2

\begin{tabular}{ccccc}
\hline Sedang & 43 & 65.2 & 0,0 & 0,0 \\
\hline Berat & 3 & 4.5 & 0,0 & 00 \\
\hline Total & 66 & 100 & 66 & 100 \\
\hline
\end{tabular}

Hasil analisis data diatas menunjukan bahwa, terapi Senam Otak (Brain Gym) yang diberikan berpengaruh terhadap tingkat stres pada mahasiswa akhir dengan nilai $\mathrm{p}$ yaitu $0,000 \quad(\mathrm{p}<0,05)$ dengan menggunakan uji Wilcoxon. Berdasarkan hasil tabel diatas posttest dan pretest diperoleh bahwa tidak ada ranking penggurangan bernilai negative. Pada tabel diatas juga diperoleh nilai signifikan nilai $\mathrm{p}$-value $=0,000$. Nilai $p$-value $<\alpha$, maka kesimpulan Ho ditolak, hal ini berarti terdapat pengaruh terapi senam otak (Brain Gym) terhadap tingkat stres mahasiswa akhir semester 8

\section{PEMBAHASAN}

Hasil penelitian didapatkan bahwa sebagian besar Tingkat Stres pada mahasiswa sebelum diberikan perlakuan termasuk dalam kategori sedang adalah 43 orang $(65,2 \%)$.

Mahasiswa adalah sekumpulan orang yang sedang menuntun ilmu di perguruan tinggi. Mahasiswa dipersiapkan menjadi sumber daya manusia yang mampu menghadapi persaingan global, sehingga sampai saat ini mahasiswa masih menjadi tumpuan dan harapan bangsa. Sebagai syarat kelulusan pada mahasiswa tingkat akhir salah satunya mengerjakan tugas akhir yang sering disebut skripsi (susane,2017).

Hasil penelitian ini juga diperkuat oleh Kun Ika Nur Rahayu (2017) Menyatakan bahwa mahasiswa mengalami stres dari berbagai sumber, baik masalah akademik yang kaitannya dengan kegagalan mahasiswa dalam menyelesaikan tuntutan akademik, penundaan penyelesaian tugas, prestasi akademik yang rendah, dan masalah penyusunan skripsi. Sumber stres akademik meliputi yang seperti, kebisingan, tugas yang terlalu banyak, sering menunda penyusunan skripsi , harapan yang tidak sesuai keinginan , ketidakjelasan, kurang adanya kontrol keadaan, tidak dihargai, diacuhkan, kehilangan kesempatan, aturan yang membingungkan, tuntutan yang saling bertentangan, dan deadline tugas perkuliahan.

Hasil peneliti ini juga diperkuat oleh Rina Rosanty (2014) menyatakan bahwa stres mahasiswa terjadi karena mahasiswa yang sedang menyusun skripsi mengalami hambatan diantaranya kesulitan mencari refrensi, sulitnya memperoleh data di lapangan, merasa cemas, takut dan tegang saat ingin bertemu dosen pembimbing, kurang konsentrasi, sehingga membutuhkan waktu yang lama dalam menyelesaikannya.

Hasil penelitin ini diperkuat oleh Dwi Widya Ningrum ( 2011) bagi para mahasiswa, ternyata tugas skripsi tersebut merupakan tugas yang tidak ringan. Pada umumnya perjalanan studi mahasiswa menjadi tersendat -sendat atau terhambat ketika menyusun skripsi. Mahasiswa pada awalnya memiliki semangat, motivasi dan minat yang tinggi terhadap skripsi namun keadaan itu menurun seiring dengan kesulitan - kesulitan yang dialami. Kesulitan itu membuat mahasiswa sering putus asa dan menyebabkan mahasiswa tidak dapat menyelesaikan studinya tepat waktu

Menurut peneliti beberapa hal yang menunjukan terjadinya stres antara lain mahasiswa menunda waktu penyusunan, harapan yang tidak sesuai keinginan,

Balimedikajurnal.com 
BMJ. Vol 6 No 2, 2019: 155-162

ISSN : 2615-7047

DOI: https://doi.org/10.36376/bmj.v6i2

susahnya untuk mencari refrensi dan takut untuk bertemu dosen pembimbing, dari semua hal yang diatas dapat menyebabkan mahasiswa mengalami stres dalam penyusunan tugas akhir atau disebut dengan skripsi.

\section{SIMPULAN DAN SARAN}

Berdasarkan hasil analisis dan pembahasan tentang pengaruh senam otak (Brain Gym) terhadap tingkat stres mahasiswa akhir semester 8 di STIKes Wira Medika Bali ditarik kesimpulan sebagai berikut, Adanya pengaruh terapi senam otak terhadap tingkat stres mahasiswa akhir semester 8 di STIKes WIra Medika Bali dengan nilai $\mathrm{p}=0,000(\alpha<0,05)$.

Berdasarkan hasil dari penelitian ini adanya pengaruh senam otak terhadap tingkat stres mahasiswa akhir semester 8 di STIKes Wira MEdika Bali maka dapat disarankan sebagai berikut

1. Bagi Mahasiswa

Diharapkan mahasiswa dapat melakukan gerakan-gerakan sederhana senam otak (Brain Gym) dalam membantu untuk mengurangi tingkat stres pada saat menjalankan tugas akhir atau penyusunan skripsi.

2. Kepada peneliti selanjutnya

1) Diharapkan kepada peneliti selanjutnya agar menggunakan metode quasi exsperimen agar ada pembanding untuk melakukan penelitian.

2) Menggunakan ruangan dengan nyaman dan tenang agar dalam melakukan kegiatan respoden dapat optimal untuk melakukan terapi tersebut.

\section{UCAPAN TERIMAKASIH}

Puji syukur peneliti ucapkan ke hadirat Tuhan Yang Maha Esa, karena berkat rahmat dan karuniaNya, peneliti dapat menyelesaikan skripsi yang berjudul "Pengaruh Senam Otak (Brain Gym) terhadap Tingkat Stres Mahasiswa ( Studi di lakukan pada mahasiswa akhir semester 8 angkatan 9 STIKes Wira Medika Bali.

Skripsi ini disusun dalam rangka memenuhi sebagaian persyaratan untuk memperoleh gelar Sarjana Keperawatan pada Program Studi Keperawatan, Sekolah Tinggi Ilmu Kesehatan Wira Medika Bali.

Dalam penyusunan ini penelitian ini, peneliti banyak mendapat bantuan sejak awal sampai terselesaikannya penelitian ini, untuk itu dengan segala hormat dan kerendahan hati, peneliti menyampaikan penghargaan dan terima kasih yang sebesa-besarnya kepada:

1. Drs. I Dewa Agung Ketut Sudarsana.,MM, selaku Ketua STIKes Wira Medika Bali.

2. Ns. Ni Luh Putu Dewi Puspawati,S.Kep.,M.Kes. selaku ketua Program Studi Ilmu Keperawatan STIKes Wira Medika Bali.

3. A.A Sri Agung Adilatri S.Kep, M.M , selaku pembimbing I yang telah memberikan bimbingan dalam penyelesaian skripsi penelitian ini serta dengan penuh kesabaran memberikan pertimbangan-pertimbangan guna terselesaikannya skripsi ini. 
BMJ. Vol 6 No 2, 2019: 155-162

DOI: https://doi.org/10.36376/bmj.v6i2

4. Ika Setya Purwanti SKM, M.Epid, selaku pembimbing II yang telah memberikan bimbingan dalam penyelesaian skripsi penelitian ini serta dengan penuh kesabaran memberikan pertimbangan-pertimbangan guna terselesaikannya skripsi ini.

5. Orang tua (Alm) Drs I Gede Suyana M.Si dan Dra Ni Nengah Suparti M.Si serta kakak kandung Ni Putu Risma Agustiari yang sedang opname di RSJ atas segala doa, cinta dan kasih sayang serta dukungan baik moril maupun material dalam menyelesaikan penelitian ini.

6. Teman teman A9-B mahasiswa STIKes Wira Medika Bali, Angkatan 9 yang ikut serta memberi dukungan semangat, sumber penelitian dan membantu dalam penyusunan penelitian ini.

7. Team Suport "DOA Foto Copy" yang sudah selalu membantu dalam penelitian ini.

8. Pihak lain yang tidak bisa disebutkan satu persatu yang telah membantu dalam menyelesaikan dan telah mendoakan demi suksesnya penelitian ini.

Peneliti menyadari masih banyak keterbatasan dalam penyusunan penelitian ini. Peneliti telah berusaha dengan segenap kemampuan dalam menuangkan pemikiran ke dalam penelitian ini, tentunya akan masih banyak ditemukan hal-hal yang masih perlu diperbaiki. Peneliti sangat mengharapkan kritik dan saran guna menyempurnakan penelitian ini.

\section{DAFTAR PUSTAKA}

Hawari, D. 2016. Manajemen Stres Cemas dan Depresi. Jakarta : FKUI .(2018). Buku Panduan Lengkap Brain Gym (senam otak). Terjemahan Oleh Ruslan dan Morris, Rahayu. Jakarta :Grasindo

( Kun Ika Rahayu ., 2017 ) Brain Gym Terhadap Tingkat Stres Pada Mahasiswa Program Studi Ilmu Keperawatan Fakultas Ilmu Kesehatan Universitas Kadiri., Dunia Keperawatan.:Kadiri.

Lovibond and Lovibond (2011). DASS(http//www2.psy.unsw.edu.au/group/dass/) diakses 2016.

Mubarak, W. I. Indrawati, L, and Susanto, J. (2015) Buku Ajar Ilmu Keperawatan Dasar. Jakarta : Salemba Medika

(Ni Putu Aniek Ratna Sari, 2015). Pengaruh Senam Otak Terhadap Tingkat Stres Lansia di Panti Sosial Tresna Werdha Jara Mara Pati Singaraja. Jurnal Keperawatan Sriwijaya.

Nursalam. 2016. Metodelogi Penelitian Ilmu Keperawatan Pendekatan Praktis Edisi 4. Jakarta : Salemba Medika.

Pratama ,M.R. 2014. Hubungan Motivasi Akademik dengan Tingkat Stres Akademik Mahasiswa Keperawatan Semester VI STIKES Aisyiyah Yogyakarta.

Primadita, A. (2012). Efektifitas Intervensi Terapi Musik Klasik Terhadap Stres Dalam Menyusun Skripsi Pada Mahasiswa Psik Undip Semarang. Skripsi tidak diterbitkan Semarang: Program Studi Ilmu Keperawatan Fakultas Kedokteran Universitas Diponogoro. 
BMJ. Vol 6 No 2, 2019: 155-162

DOI: https://doi.org/10.36376/bmj.v6i2

Purwati, S . (2012) 'Tingkat Stres Akademik pada Mahasiswa Reguler Angkatan 2010 Fakultas Ilmu Keperawatan Universitas Indonesia Tingkat Stres Akademik pada Mahasiswa Reguler Angkatan 2010.

Rina Rosanty (2014) journal ofducation, health and community psychology vol .3, No 2, 2014

Rahady, I.P.D 2014. Hubungan Self-Efficacy dengan Tingkat Stres Mahasiswa dalam Menyusun Skripi.

Setiadi . (2010) Konsep dan Penulisan Riset Keperawatan Edisi Pertama. Yogyakarta. Graha Ilmu.

Smeltzer, S.C and Bare, B. G. (2015) Buku Ajar Keperawatan Medikal-Bedah. Jakarta:Salemba Medika.

Susane L,I.M A 2017. Hubungan Tingkat Stres Terhadap Motivasi Mahasiswa Dalam Menyelesaikan Skripsi Pada Mahasiswa Tingkat Akhir Di Fakultas Kedokteran Universitas Lampung.

Suryanto 2011. Metodologi dan Aplikasi Penelitian Keperawatan. Yogyakarta : Nuha Medika.

Sugiyono . (2018) Metode Penelitian Kuantitatif Kualitatif dan R \& D. Bandung, Alfabeta.

WHO (2012). Masalah Kesehatan Jiwa Akibat Stres. 